Sport, Education and Society

\title{
Abjection and alterity in the imagining of transgender in physical education and sport: a pedagogical approach in higher education
}

\author{
Víctor Pérez-Samaniego, Jorge Fuentes-Miguel, Sofía Pereira-García \& José \\ Devís-Devís
}

To cite this article: Víctor Pérez-Samaniego, Jorge Fuentes-Miguel, Sofía Pereira-García \& José Devís-Devís (2016) Abjection and alterity in the imagining of transgender in physical education and sport: a pedagogical approach in higher education, Sport, Education and Society, 21:7, 985-1002, DOI: $10.1080 / 13573322.2014 .981253$

To link to this article: http://dx.doi.org/10.1080/13573322.2014.981253

\section{Published online: 20 Nov 2014.}

Submit your article to this journal $₫$

Џll Article views: 527

Q View related articles $₫$

View Crossmark data $\asymp$

Citing articles: 6 View citing articles 


\section{Abjection and alterity in the imagining of transgender in physical education and sport: a pedagogical approach in higher education}

Víctor Pérez-Samaniego ${ }^{a}$, Jorge Fuentes-Miguel ${ }^{\mathrm{b}}$, Sofía Pereira-García ${ }^{\mathrm{a}}$ and José Devís-Devís ${ }^{\mathrm{a} \star}$

${ }^{a}$ Facultad de Ciencias de la Actividad Física y el Deporte, Universitat de València, Valencia, Spain; ${ }^{\mathrm{b}}$ Facultad de Magisterio, Universitat de València, Valencia, Spain

In physical education (PE) and sports there is little theoretical and empirical knowledge about transgender people, and particularly, on how they are and can be imagined within this context. In this paper, we present and analyze a pedagogical activity based on the reading and discussion of a fictional representation of a transgender person within a group of undergraduate students of Sport Sciences. Our theoretical frame situates abjection and alterity as opposing concepts on a continuum. Results show several ways in which a transgender person is imagined by students, as well as constraints and possibilities for the pedagogical proposal to promote moral imagining of transgender. Students situated in abjection justify their rejection of transgender persons, bringing up compassion (such as pity), genitalization, symbolic violence and stigmatization of transgender persons. The realm between abjection and alterity is characterized by tolerance of different normalities, as well as linguistic constraints hindering the acceptance of transgender people. In alterity, students acknowledge their limited ability to totally imagine what it is like to be transgender, and also, their will to encounter transgender persons face-to-face. Although results of this experience should not be interpreted in a prescriptive way, they show different ways to imagine transgender people in the domain of PE and sports, as well as the importance of considering the ethics of alterity as a means to advance in the moral imagining of transgender persons and, in general, of the distant Other.

Keywords: Symbolic violence; Thematization; Compassion; Acceptance; Tolerance; Dialogue

\section{Introduction}

Issues facing transgender people are of a growing concern in academic and educational domains. However, there is a lack of research in relation to physical

${ }^{\star}$ Corresponding author. Facultad de Ciencias de la Actividad Física y el Deporte, Universitat de València, C/ Gascó Oliag, 3,Valencia 46010, Spain. Email: jose.devis@uv.es 
activity, physical education (PE) and sport, at least in comparison to research on lesbian and gay issues (Caudwell, 2014). In particular, there is little theoretical and empirical knowledge about pedagogical approaches on transgender in the context of higher education PE and sport classes. In Spain, for example, it is likely that PE and Sport Science students, who may meet transgender people along their professional life, finish their studies without any opportunity to, at least, imaginatively connect with transgender persons. However, transgender people go to schools and may practice sports. They may exercise for fun, for health or for the sake of constructing their embodied identity, just like the rest of the general population. PE and sports professionals may play a small, though significant role either to reinforce or to weaken barriers that hinder transgender people with regard to their practice of sport and physical activity. Furthermore, their practices and beliefs may have an impact beyond the realm of sports and physical activity, influencing social acceptance of diversity in gender identities and contest transphobia as a form of gender oppression.

Transgender frequently challenge assumed beliefs on embodiment, gender and identity and, from this regard, it occupies a significant position in any contemporary analysis on those issues. The mere existence of transgender people becomes an objection to the central role of sex-gender binarism in the sociocultural apparatus that determines what a gendered-body should be and should aim to be. In this sense, concerns about transgender are also concerns about dimmed but powerful forms of social control rooted in the discussion about who should decide who we are and how our own body ought to be. Thus, pedagogical initiatives in higher education to imaginatively connect students with transgender persons, such as the one presented here, may contribute to the emergence of other possible understandings of transgender, as well as challenge views usually taken for granted regarding gender in $\mathrm{PE}$ and sport.

\section{Theoretical framework}

Gendered body, as Caudwell (2014) notes, 'remains central to processes of exclusion, rejection and abjectification' (p. 399). This is particularly so for other gendering bodies and identities, such as the ones represented by transgender people. In order to frame the understanding of transgender and particularly, on how transgender people could be imagined by those who are not, our theoretical background calls upon the concepts of abjection and alterity.

Abjection, literally means to cast off, away or out and, hence, presupposes and produces a domain of agency between the abjecting and the abjected, from which the former is differentiated. Kristeva (1982) presents the concept of abjection in relation to the construction of psychic and social subjects. For Kristeva abjection is often associated with something that individuals are disgusted by (e.g. dirt, excrements, menstrual blood). Referring to the construction of self, abjection works as the symbolical pushing away or expelling of anything or anyone revolting to us. As so, acts of abjection become key moments in the process to meet and draw the limits of 
acceptable self: through abjection the acceptable subject meets its contours and draws a border beyond which subjects cannot be accepted.

Butler $(1990,1993)$ highlights Kristeva's conception of abjection in order to better understand the construction of gender identity. For Butler (1990), abjected bodyselves 'fall outside the human, indeed, constitute the domain of the dehumanized and the abject against which the human itself is constituted' (p. 111). Specifically, abjection excludes those who do not fit into the regulatory ideal of gender binarism. The wider the distance from idealized binarism, the more abjected the actual bodyself is considered. As remarked by trans scholarship, the distance with normative body is so broad that, in part, limits of gender/sex binarism can be drawn at the expense of abjectifying transgender (see Halberstam, 1995; Stryker, 2006). Transgender would constitute an example of abjection per se, as long as no correspondence at all between sex and gender can be socially perceived.

Beyond theoretical discussion, Butler (1993, p. 243) remarks that human beings actually live in the 'unlivable' and 'uninhabitable' zones of abjection. By underlining the artificial, proscribed and performative nature of gender identity, Butler also seeks to trouble the definition of abjection, challenging the status quo of marginalized gender identities. Not only in a heteronormative system, abjection is also constructed through discursive practices and the flow of identifications and non-identifications in the building of different gender identities.

Alterity is the second key theoretical concept in our interpretive framework. Alterity can be characterized as a person's otherness that precedes any attributes. As Levinas puts it, alterity is pre-existent to human nature and it is not contingent. That means that otherness is not dependent on what may happen to us, nor is it determined by what we do or have, but rather by what we are. We are all absolute Others to the others, as Levinas stresses: 'An individual is other to the other. A formal alterity: one is not the other, whatever its content. Each is other to other' (see Robbins, 2001, p. 162).

Alterity deeply affects the conception and the practice of our relation with otherness and, specifically, our ability to imagine the other (Smith, 2008). As so, any attempt to empathetically grasp the other's lived experience, to place oneself in his or her shoes or to imagine ourselves being another person is necessarily constrained and elusive. This, however, does not mean that we should abandon any effort to imagine others. Rather, it means that we need to recognize the limits of our imagination and encounter the other as other rather than on our own terms. For Levinas, respecting and preserving alterity becomes essential when we meet with unnecessary suffering. Then, we become impelled by the other. As Levinas states 'if you encounter the face, responsibility arises in the strangeness of the other and in his misery. The face offers itself to your compassion and to your obligation' (see Robbins, 2001, p. 48). Basically, ethics of alterity calls on our responsibility to respond to this allegorical encounter with the face of the other, to whom we are obliged to respond. However, Levinas suggests a balance is needed between absolute distance and absolutely proximity with the Other. That is, recognizing the other as the other and 
being responsible for him or her without appropriating the words which explain someone else's experiences.

In education, the ethics of alterity brings out concerns about the imagining of a transgender by non-transgender or cisgender persons. First of all, we must acknowledge that transgender people are others as any other is other to oneself, independent to any specific attribute. In other words, transgender people should not be considered Others just for being transgender people. Moreover, it means recognizing that there is not a single way of being transgender, as there is not a single way of being cisgender. However, it is difficult to deny that transgender people may suffer because of their social consideration as abjected body-selves (Stryker, 2006). Therefore, as educators we are obliged to respond to the moral imagining of transgender people, especially to their sufferance, in the domain of PE and sports.

\section{Purpose and objectives}

This paper stems from our interest, both as university educators and researchers, in responding to the potential encounter of transgender people in PE and sport via their moral imagining. For this purpose, in this paper abjection and alterity are presented as two ends of a continuum. In doing so, we intend to problematize essential concepts in dealing with the imagining of transgender people in order to gain understanding on how these concepts evolve along the continuum, and how students position themselves towards them. We also intend to reflect on the sense and direction of pedagogical approaches to transgender, and obtain empirical evidence on the possibilities and limitations of a pedagogical approach proposed to give access to the imagining of transgender individuals. Therefore, we have designed and developed a range of activities to provide and share insights on how sports, PE and physical activity may be experienced and lived by transgender people, as well as to promote dialogue between different perspectives on that issue.

The purposes of the study and the pedagogical practice are synthesized in these interrelated research questions: how transgender people are imagined in the context of sports and PE? Can we sensitize students to the moral imagining of transgender people?

\section{Method}

\section{Participants}

Sixty-one fourth year students of Sport Sciences at the University of Valencia, aged 20-26, participated in the pedagogical initiative, which took place in March 2012. The activity was incorporated into a subject which included gender education. It was developed by two of the authors of this paper, neither of whom were lecturers of that subject. At the beginning of the session, it was clearly stated to the students that the activity was not an assessment, and that they were free to withdraw without any 
further explanation. Written consent to record data was requested from the students in order to use it for research purposes.

\section{Fictional tale and its role}

In our activity, we have privileged the use of fiction as a research based teaching strategy to access and give access to the otherness represented by transgender people. Written by Jorge Fuentes-Miguel, the tale 'Escaping from My Body' tells the story of Mar, an adult transgender woman formerly named Mario, who started her transition from male to female during her late days in secondary school. Throughout her story, Mar recalls both her good and bad experiences in PE and sports: the support and bullying of schoolmates, her love and horror for certain PE activities, her problematic relationship with some of the teachers and trainers, her struggle in the dressing rooms, etc. The text is evocatively written, inviting readers to emotionally engage with the reading and to see beyond the facts told. Many of the events are inspired by the author's experience as a PE teacher, his personal acquaintance with some transgender people, as well as conversations and interviews with transgender people carried out as a part of a wider research project. However, it must be noted that Mar and the other characters of the tale were invented, and all the events, times and places were created by the author. Accordingly, the relation of the text with reality and the way it is recreated make 'Escaping from My Body' a piece of creative fiction.

A lot has been written about the possibilities and limitations of fiction as a legitimate representation of research, as well as the criteria and ways to assess and improve the quality of this type of work and its practical utility (e.g. Sparkes \& Smith, 2009). Being ourselves cisgender pedagogues, for us creative fiction has become a unique means to access and give access to the imagining of what a transgender person may experience in PE and sports. In this sense, it allowed us to perceive and share aspects, nuances, social exchanges and phenomena that may be unfamiliar, distant or invisible, facilitating new ways of seeing and expand our perspectives to understand transgender realities as they could be experienced. This process of empathetic imagination (Smith, 2008) and internal reflective deliberation (Spindler, 2008) may serve to meet and reflect on situations, experiences and challenges of Others, offering a new perspective on their lives, and also dampen conflict when stories shared might affect core beliefs of the readers.

\section{Procedure and data collection}

The pedagogical experience commenced with the reading of the tale 'Escaping from My Body', for approximately 15 minutes. Then, students received a sheet of paper with the following questions: Who is Mar, a man, a woman or ...? And What does 'normal' mean to you in terms of sex or gender? The heading explained that their written thoughts and opinions about those questions formed part of a research project about gender identities and that their participation was voluntary, ensuring anonymity in any case. Students completed their written opinions which were collected and 
returned to them again in a random order, so that each one received a text by an unknown author. A group discussion was opened by a volunteer who read aloud the anonymous text that was in his hands, alternating thereafter with readings and personal opinions about the different readings. This procedure allowed students to learn their peers' views about the tale and to feel free to comment their views regardless of its authorship. The discussion provided the opportunity to reveal on the spot different imaginative approaches of students to transgender people.

According to Ellsworth (1997, p. 8), in anti-oppressive pedagogies certain paradoxes on how teachers 'make a difference in power, knowledge, and desire' may generate tensions due not only to what teachers teach, but by how they address students. In this activity we faced specific tensions due to students' and pedagogues' gender identities and their effect on a pedagogical approach to transgender. We cannot deny that the intentions and design of the pedagogical practice were somehow influenced by our preconceptions about transgender people and students' identities. Particularly, being cisgender researchers and pedagogues ourselves, it would have been easy, as Caudwell (2014) rightly remarks, to unwittingly assume and perpetuate the existence of a binary system in our way to refer to and about transgender persons. This may have been the case insofar as the aim of imagining transgender people presuming that the students were also cisgender persons, and that shared fixed preconceptions of transgender should be modified.

However, in order to respectfully address the potential diversity of the audience, our pedagogical fictional based approach to transgender was informed by a modest pedagogy that, according to Tinning (2002), problematizes knowledge and schooling, as well as avoids simplistic dualisms, lack of diversity and students' subjectivity negligence. With that in mind, the above mentioned procedure resisted any finalising interpretations of the story, and its discussion privileged the last word of students, thus providing them with certain power and space to construct, share and negotiate their own thinking and feelings about transgender from their own embodied identities. Consequently, we sought to make all the students who read the fictional piece and participate in the discussion feel respected and invited to contribute from their own vantage point, including those who might have identified with transgender identities (if it were indeed the case).

The discussion ended when the students considered there was nothing else relevant to be told, and when their own opinions had been sufficiently discussed in the public debate. It lasted about 40 minutes, and was recorded with the consent of the participants. The written answers were collected by the researchers ('Responses' in data), and the recorded discussion was translated verbatim ('Discussion' in data).

After the reading and discussion, one of the researchers gave a 20 minute lecture about the sex-gender binary system and its limitations regarding transgender people. The purpose of the lecture was to provide the students with some knowledge that might inspire further meditation about opinions that had been posed during the discussion. In order to achieve this second level of reflection, students were introduced to a blog entitled 'Escape from my body' (http://escapardemicuerpo. blogspot.com), in which the tale is accessible, and they were invited to nominally or 
anonymously participate in the blog with their comments. Two weeks after the activity, the blog had 12 postings (20\% of participants from the first activity) that were incorporated to the written reflections and the verbatim transcript of the debate as data for analysis ('Blog' in data).

\section{Analysis}

Once collected, researchers focused on analyzing and providing plausible interpretations about the data. Initially, the process started with inductive thematic analysis in order to identify themes within the data (Braun \& Clarke, 2006). The research team read through, reorganized and made descriptive, exploratory comments about the data by underlining recurring phrases and highlighting key concepts. During this first stage, the analysis focused on identifying emerging thematic categories and conceptual connections with literature. At this preliminary phase, several concepts were raised such as body-self relations, respect, tolerance, empathy, responsibility and compassion. Along this process, certain polarization in the student's impressions on those themes became apparent. For instance, while some students considered Mar (or Mario) to be 'abnormal' or 'ill', others outlined their admiration for her struggle to become 'what she is'. After identifying this polarization, literature on alterity and abjection was then accessed and used as a framing device for the analysis of emergent themes. That is, the consideration of abjection and alterity as opposed poles of a continuum was not aprioristic. Rather, it was grounded in the specific characteristics of the collected data.

\section{Results and discussion}

\section{Transgender as abjection}

The majority of the comments gathered from the students' written answers showed that they considered transgender people to be deviated or abnormal body-selves. The following quotes are some of the many that illustrate how biological norm functions as the essence towards which the degree of deviation is imputed.

Fortunately I am a boy in a boy's body, and I wouldn't change that for anything. (Responses)

That is, if you're born a man, it is normal to act and feel as such (since men and women are different, as shown by multiple studies), and the same in the case of women. But there are some exceptions that require treatment. (Responses)

Gender is what it is. To me it is not possible to change it. Everyone is born with problems and has to accept them. (Responses)

At this early stage of the activity, the former quotes show different ways in which students refer to gender binarism and biological norm, not only as a description of sex-gender characteristics, but also as an ideal which neglects the very possibility of human beings to be anything else but authentic men or women. For Butler (1990) the 
legitimating of sex-gender binarism as the norm against which any other gendered body self is to be considered functions performativity as an act of expulsion:

This appears as an expulsion of alien elements but the alien is effectively established through this expulsion. The construction of the 'not-me' as the abject establishes the boundaries of the body which are also the first contours of the subject. (p. 133)

In this mapping of body selves, abjection draws the limit beyond which body deviation defines selves. Beyond that limit transgender people are thematized, that is, they are put into a category as deviated, assuming a kind of knowledge or truth-claim about them that forecloses difference and, thereby, do violence (Holland, 2003). Thematization would lead to what Levinas (1974) calls totalization: the absorption of individual differences of the Other by truths and values determined by reference to myself and I. As Shepherd (2003) stresses, totalization occurs whenever the $I$ limits the Other to a set of rational categories (racial, sexual or otherwise) already knowing what the Other is about before the other has spoken. Scientific knowledge, with its apparent neutrality and objectivity, becomes the perfect alibi for the $I$ to totalize the other. In fact, as seen in the quotes above, often certain scientific evidences are mentioned to back up derogatory claims towards social groups being discriminated. Among the several strategies used to provide content to thematization and totalization of transgender as deviated persons, pathologization must be highlighted. In fact, even within the transgender community, there is controversy as to whether transgender people can be considered to have a Gender Identity Disorder (O'Neil, McWhirter, \& Cerezo, 2008). However, it is rather unlikely that student's remarks to a supposedly scientific basis of gender normativity could have any link with this debate. Most probably, it assumes the obvious need to treat abjected body selves in order to be cured.

When facing an alien other, empathy is often presupposed as a means to gain understanding and to attain knowledge by imaginatively putting ourselves in the place of the others (Smith, 2008). Not surprisingly, in abjection empathy towards transgender people fails, as illustrated in the following quotes:

I can't come to understand that things like those described in the text [referring to fictional story] may actually happen. That some people feel like they are the opposite sex ... It is not natural. I think the debate is closed. (Responses)

The text [referring to 'Escaping from my body'] does not change my way of thinking, but it helps me put myself in the other person's shoes-someone who is discriminated. Nature is wise and each gender is made to reproduce with the opposite sex. However, there are people who are not happy with the body they have to live in ... however, thanks to surgery they can change their body. The ordeal they must go through in their life is pretty strong. In my opinion society is not ready for this, but it is quite normal because it is unnatural. (Responses)

The first quote openly acknowledges the impossibility of any empathetic imagining of transgender people. Again, appeals to a self-evident natural order is implicitly used to justify abjection of transgender people, placing them beyond the limits of what is considered human, categorizing them as 'the excessive dimension of subject that 
cannot be assimilated' (Butler, 1993, p. 58). Consequently, transgender persons are seen as charged with negativity, and any attempt to imagine the living experience of transgender people turns into an erratic diagnosis of the causes and effects, proposing solutions to revert their deviation, as shown in the second quote. Paradoxically, in this comment the student mentions the effect the reading had on improving his/her empathetic ability 'to put himself/herself in the shoes of someone who is discriminated'. However, this apparent empathetic advance is ethically irrelevant, as the 'ordeal lived by them' becomes justified by the 'unnatural' condition of being a transgender person.

Besides the limited effect of the activity in changing student's beliefs, this incongruity reveals how abjection turns empathetic imagination into symbolic violence. As Frank (2004, p. 115) argues, empathy risks the symbolic violence of telling the Other how to feel better. Symbolic violence takes place when the $I$ tells the others 'that they should not be who they are, or that they fail to understand who they ought to be'. This would be the case of natural human beings telling transgender who they are, or what they ought to be, and how they should feel about it. Moreover, putting the natural condition of the body as a prerequisite impairs any empathetic imagination with transgender persons because, as Stryker (2006, p. 238) remarks, a transgender body actually is 'an unnatural body. It is a product of medical science. It is a technological construction'. Confronted with human sufferance, empathy often turns into compassion. Literally 'compassion' means to suffer-together-with. We usually feel compassion for good reasons; our emotional response to someone else's suffering 'can prompt us to sort through those reasons, to discover the conditions that cause that suffering, and to improve our judgment' (Shepherd, 2003, p. 445). However, this may not be the case when compassion is exerted towards the abject, as reflected in this quote:

Everyone can do what he pleases at home, as long as he respects others and does not disturb anyone. However, my doubts are: Should these people be able to have a family or children? If we normalize all these ways of understanding life, will there be increasingly more people who change their sex? Finally, I am thankful for being normal and feel good about it. I feel compassion for those who are not. (Responses)

Compassion entails respect for the sufferance of others, and a call to help others. Considering their discrimination and vulnerability as a social group, it would be expected they any compassionate claim would focus on the sufferance of transgender. However, in this quote it is implicitly suggested that normative body-selves are to be respected by transgender people. Moreover, as long as normative selves could feel 'disturbed' by the presence of transgender people, this comment also suggests that transgender would be acceptable only in private, thus following the guiding principle 'don't ask, don't tell' often adopted to admit gays and lesbians in certain social domains. In Holland's (2003) opinion, though, this policy is humiliating and unfair, as it refuses to accord them the same basic human needs (not just rights) accorded to the rest of the population. Moreover, in the case of transgender people it would be also inoperative because most of the times being transgender is difficult to disguise since it leads to public recognition of a new personal and social identity. 
This would be particularly so in the context of PE and sports, in which the appearance and performance of the body constantly expose gendered selves to social scrutiny.

Since the normative body-selves appear in the above mentioned quote as the nonrespected ones, a claim for compassion based in this sort of inversion between the ones suffering and the ones causing sufferance becomes regressive and intrusive, evoking pity instead of true respect for transgender people. In fact, as Shepherd (2003) suggests, a person can feel compassionate without liking or respecting a particular stranger before her/him, thus appropriating the sufferance of the other by filtering the other's experiences through his/her own eyes. In some way, he argues that compassion is too easy since it suggests an understanding of what your needs and desires would be if you found yourself in that condition, but does not require the intense effort necessary to understand the needs and desires of the suffering person as that person.

Constraints for empathetic imagination and compassion provoke statements about transgender people underscoring their stigmatization and monstrosity, as illustrated in the following quote:

These people are insane. They should be exhibited in a circus or something similar. I find it disgusting. And I cannot understand why we have to pay [taxes] for their medical treatments. (Responses)

Butler (1993, p. 150) highlights the metaphor of circus monstrosity, 'a spectacle, entertaining and terrifying', in order to reflect the gruesome depiction that normative selves made of the abjected. As in the tale of Frankenstein, Stryker (2006, p. 8) finds that because of her unnatural transgender body, she is too often perceived as less than fully human and 'like the monster's as well, my exclusion from human community fuels deep and abiding rage in me'.

For the proper $I$, with its clear and defined boundaries, the mere consideration of these non-human beings is threatening and horrifying. The abject, which is something improper, poses a threat to the ego. Abjection creates 'the status for the subject as a threatening specter' (Butler, 1993, p.3). Remarkably, in the case of transgender this ghastly totalization is determined by supposedly inaccurate relations between gender identity and genitals. Thus, transgender persons are genitalized, that is, they are thematized as persons with the wrong genitals and, consequently, stigmatized as monsters. Beyond any discussion on the idea of right or wrong applied to the relation between biology, gendered body and self, genitalization would be unfair and biased as it totalizes a transgender person into a single attribute, while nothing is known about 'her dreams, her actual abilities or disabilities, or her capacity to love and be loved' (Shepherd, 2003, p. 466).

\section{From abjection to alterity}

In the continuum represented in Figure 1, the relation between abjection and alterity is dynamic, and consequently, there are certain indeterminate zones in which 


\author{
Rejection \\ Binary gender/sex fundamentalism \\ Respect of transgender people \\ Compassion as pity \\ Thematization (genitalization) \\ Stigmatization \\ Symbolic violence
}

\author{
Tolerance \\ Normalities \\ Linguistic constraints
}

\author{
Encounter \\ Absolute distance and proximity \\ Focus on sufferance \\ Responsibility for transgender persons \\ Dialogue \\ Rupture
}

\section{Pedagogical sense and intention}

Figure 1. Abjection and alterity in the pedagogical approach to the imagining of transgender

students' comments may be interpreted as attempts to abandon abjection without connecting to alterity. This happen, for instance, with certain remarks about normality:

Maybe it [reading of 'Escaping from my Body'] has helped me to understand more about this kind of situation and to take more into account the feelings of each person not just on the basis of what is considered 'normal'. (Responses)

As Jorge [name of teacher] explained in class, we usually consider only two forms of gender and sex relationships, men masculinized and women feminized. Something that differs from these stereotypes we consider 'weird' or something that is not 'normal' and therefore, a source of ridicule and harassment. But, what does it mean to be 'normal'? (Blog)

Basically, what is questioned in these comments is binary fundamentalism in gendersex relations which, as seen in the former section, lay in the very heart of abjection. The rhetorical question 'What does it mean to be normal?' suggests that not only natural body-selves, but also transgender selves may be considered normal, thus widening the limits of normality. This could be interpreted as a call to those who are already considered normal to tolerate those who may also be considered normal.

When applied to transgender, tolerance becomes a problematic point. Tolerance is a permissive attitude exerted by someone who tolerates someone else who is tolerated. This could have positive consequences as the acceptance of different views and coexisting truths on gender identities would facilitate recognition and acceptance of transgender within the social space. However, tolerance also implies that there is always something or someone who exerts the power to determine what is acceptable and, consequently, what is not. Holland (2003) suggests that no matter how well intentioned they are, discourses based on tolerance may rather be considered strategies to disguise exclusion of the unacceptable other. Thus tolerance, he argues, 'is not a sufficient basis for ethics and may actually bring about unintended harm' (p. 166).

Tolerance is especially controversial when the tolerated ones belong to a social group that is particularly vulnerable and difficult to classify. As Caudwell (2014) 
remarks even within lesbian, gay, bisexual and transgender (LGTB) people, a hierarchy of (in)visibility exists in which the ' $\mathrm{T}$ ' (for transgender) tends to slip from view and, consequently, gets ignored. Besides, in the domain of gender identity not all experiences of transitioning conform to the female-to-male and male-to-female categories. Within the transgender community those who accommodate the twosexed system (gender conformers) and those who destabilize that system (gender transformers) may reproduce tensions related to normative body-selves. The first would be men (or women) who aim to become women (or men). The second, would rather be called, among other names, gender queer, third gender, gender fluid, agender or genderless preferring to remain in an ambiguous territory, rejecting the status of man or woman as origin or destiny of their gender identity (Stryker, 1998). Thus, even within marginalized gender identities, binarism may become a mould which determines who deserve to be tolerated by others who may be considered deviated in relation to them.

In order to understand the nature and consequences of tolerance, one should focus on those who tolerate. The success lies not in tolerating transgender people, (not even in the more positive sense of the word), but rather in accepting them. Acceptance ends where the very presence of the concept of tolerance is undermined and compromised by normative body-selves. The tension between this claim for acceptance and its shortcomings can be seen in the following discussion about the true name of the main character of 'Escaping from my Body'. The tension heightens after reading the comment in which one student systematically referred to 'Mar' with her former masculine name of 'Mario':

Student A: IT'S MAR, NOT MARIO. IT'S MAR!!

Student B: That depends.

Student C: Are there two?

Student D: No, no, no; it's Mario

Student A: If you agree with her, then call her as she is. She's a she. She is Mar.

Student B: What Peter [fake name of student A] is saying is that the person who wrote the comment did not take into account his identity, the main character, I mean she, of Mar. [laughs]

(Discussion)

This dialogue provides a hint on how the discussion of the fictional tale provided students the opportunity to reveal, share and reflect on their beliefs about transgender people. Here, the students are not speakers of other's voices, but voices that speak for themselves. With his undoubting recognition of Mar, Student A is accepting her 'as she is', while students $\mathrm{C}$ and $\mathrm{D}$, in different degrees and manners, show a limited ability to do so. Student B, in an effort to mediate between them, gets confused in the use of pronouns when referring to Mar (or Mario). This problem is understandable, considering the difficulties many people have using appropriate language when initially referring to transgender people. Among the many alternatives 
to gender binarism in language (pronouns such as $z e$ and hir and other gender neutral terms such as partner, spouse, child, friend), O'Neil, McWhiter, and Cerezo (2008) suggest that the best terminology would be that preferred by persons to affirm their identity, whatever it may be. Regarding alterity, the issue would not be how to make an appropriate use of language, but how to use language to appropriately accept the other as other.

\section{Alterity}

Although students' comments on transgender people predominantly engaged in abjection or in the domain that we have called 'from abjection to alterity', during the activity, particularly in its late stages, some students clearly connected their interpretations of 'Escaping from my body' and their reflection about the discussion with alterity, as shown in the following comments:

Mar is a person with the body of a man who feels like a woman. Therefore, she is a woman. Whatever her physique may be, what she feels inside makes her own identity as a person. (Blog)

For me, respect is linked to acceptance (...). I mean, if you accept someone, it's because you really respect him. It's because he has every right to be there and you must respect that right. (Discussion)

An unambiguous claim for the right of Mar to decide about who she is on her own basis, as well as the call for the unavoidable relation between respect and acceptance, show students' willingness to privilege alterity over any other approach to transgender. Here, instead of being judged as deviated specimens, transgender people are encountered face-to-face. Holland (2003, p. 168) enhances the importance of the appearing of the face, 'naked, destitute before me', as a requisite for a true encounter with the other. It is as if the face of a transgender person pleads to the cisgender approaching: do not see me as you see yourself; I am not the same. I am radically different, and if you try to absorb my difference into your sameness, you will have done an extreme violence.

For Frank (2004, p. 116) 'seeing the face requires respect for alterity: I must recognize that there are aspects of your suffering that I cannot even imagine and that I can never touch'. Accordingly, most empathetic comments on the blog adopted that attitude towards transgender persons:

Inhabiting a body that does not match what you feel might make you feel very unhappy and very confined to yourself. I cannot even imagine it. (Blog)

I, at least when I read it,- it makes me feel the pain of that person but not for what she [Mar] is, but for what she suffers in her life. Yes, that makes you feel sad. But not for her, but because they make fun of her. (Blog)

Statements such as 'I cannot even imagine' not only show an empathetic will, but also somehow acknowledge a certain inability to totally imagine what is it like to be a transgender person. This recognition of the other-as-other, this 'genuine respect for heteronomy' (Holland, 2003, p. 174), however, does not hinder our encounter 
face-to-face with transgender people. On the contrary, it is the position needed for the emergence of an ethics of alterity, which focuses on responsibility for the suffering. As Levinas (1974, p. 99) puts it, 'ethics (...) is when another obsesses me or puts me in question. This putting in question does not expect that I respond; it is not a question of giving a response, but of finding oneself responsible'. For Shepherd (2003, p. 476) the distinct feature of responsibility is obligation: 'We are trapped, captured, 'held hostage' by the face of another person whose presence commands some response'.

When encountered, the face of transgender people urges our action. Here is where Levinas' idea of the encounter face to face finds its fullest meaning, as shown in the following comment:

What can you do to make people like these feel happy and integrated into the school environment? I do not know. (...) I think the situation is difficult and I would not know how to act, how far to reach out, how deep to get involved ... It's very complicated. (Blog)

The reflexive questioning 'what can you do?' in the above quote synthesizes our call to duty regarding transgender people. The question here is not what transgender persons supposedly are, but how we can fulfil our responsibility towards them. In that sense, as Shepherd (2003) reminds us, a radical responsibility would commit us since we are obligated to respond to the suffering and the needs of others, of everyone, for everything. The very first thing that we are obliged to do is to respect alterity, and that would mean a certain change in rules concerning our responsibility towards the other. Instead of 'this other person is like me, therefore I will treat him/ her like I would like him/her to treat me', from the ethics of alterity a responsible response would be 'this other person is not like me, therefore I will treat him/her according to his/her needs'.

For students studying Sport Sciences, as well as for many other people, transgender people might be distant others. Not just because it is unlikely they have any academic or personal knowledge about transgender people, but because certain embodied experiences of gender identity predispose them towards abjection, as seen earlier in this paper. Considering embodied distance with transgender people and the constraints for empathetic imagining, the question that arises is: How can I grasp the actual needs of transgender people without violating alterity? Difficulties to answer this question are somehow implicit in the complaint 'it is very complicated!' in the above quote. And in fact, it is! Encountering the face of the other is demanding. You cannot be the same when you encounter the other face-to-face, because the face of the other changes you. Shepherd (2003) calls this a rupture: 'because we see the other person outside our own referential framework, the experience of rupture goes far beyond the experience of attempting to comprehend the other person' (p. 489).

In order to deal with this rupture, tolerance and compassion become clearly limited to fuel moral imagining of transgender people. Instead, alterity requires dialogue. Levinas (see Robbins, 2001) believes that dialogue begins with the invitation of some distance, with the acceptance of otherness. For Frank (2004, 
p. 116), 'alterity is the dynamics that drive the dialogical relationship. It is the difference that makes dialogue possible, and one goal of dialogue is to sustain alterity'. Therefore, alterity sustains dialogue, but it also makes dialogue difficult, simply because the other is the other. Thus, in the process of moral imagining of transgender people sufficient distance from transgender persons is needed, however, too much distance would hinder the encounter with them. This may happen, for instance, by asking transgender people to respect what is natural or normal in terms of gender identity. But without some distance dialogue is impossible. This would occur when we compassionately merge with transgender people on the basis of what transgender people supposedly should feel or do.

\section{Closing thoughts}

Further this pedagogical experience, what answers do we have to our research questions? How are transgender people imagined in the context of sports and PE? Can we sensitize students to the moral imagining of transgender? In short, what have we learnt from our experience?

First, we have become aware of coexisting perspectives on transgender and their consequences in the imagining of transgender people. Based on a fundamentalist understanding of gender binarism, abjection not only limits but also distorts empathy and compassion as a means for moral imagining of transgender people, turning it into symbolic violence and stigmatization. When transiting from abjection to alterity, the imagining of transgender persons moves within a controversial domain of tolerance, which may turn the rather good intentions assumed in compassionate feelings towards transgender persons into a quite damaging and humiliating sense of worthlessness. From the angle of alterity, the will to encounter transgender people face-to-face emerges. Then, the imagining of transgender can be found within a delicate balance between the respect for alterity and the responsibility for others. This movement back and forth from the absolute distance and the absolute proximity is essential to promote dialogue that would overcome the risks of symbolic violence, as well as to channel the rupture that a transgender may bring to former referential frames.

Although alterity and abjection are not exactly opposite concepts, situating them as the poles of a continuum has helped us to enhance the understanding of the imagining of transgender people. The continuum allows us to realize that transgender people can be imagined differently and more respectfully, and receive the same respect that is deserved by other groups included under the umbrella of LGBT. The move from abjection towards alterity also provides a sense of direction to fulfil with unavoidable ethical concerns inherent to pedagogical approaches intended to enhance the imagining of the distant other.

The respect for anonymity has hampered the comparison of comments made by the same students throughout this activity and, consequently, we cannot determine its impact on particular students. However, it would be unrealistic and naïve (if not arrogant and dangerous), to consider that one single experience could provoke 
changes that may affect core beliefs, especially on students deeply embedded in abjection. We must stress that situating transgender at the realm of abjection does not occur purposelessly. On the contrary, it has a specific function, as it helps individuals and social groups to enhance their own corporeality. In so doing, the abjectifying of transgender people becomes part of an apparatus (concept/process) that Shilling (2007) has termed body pedagogics:

the central pedagogic means through which a culture seeks to transmit its main corporeal techniques, skills, dispositions and beliefs, the embodied experiences typically associates with acquiring or failing to acquire these attributes, and the actual embodied changes resulting from this process. (p. 13)

In this regard, abjection forms part of the apparatus of the body pedagogics of gender. The simple rationale is that to be transgender is the reverse of the biological norm. Thus, the distance between the gender identity and the biological norm represented by being transgender is too far to be accepted, and even to be imagined.

There is not a single, neat, efficient and unquestionable way to simply exchange body pedagogics of abjection for body pedagogics of alterity. Thus, our modest experience and the results of this study should not be interpreted in a prescriptive way. It would not do for us to tell the reader what he or she ought to do to promote alterity. However, at least two thoughts about the design and development of our particular approach are worth noting. First, none of students' comments and reflections about transgender people were affected by the fact that 'Escape from My Body' was a work of fiction. On the contrary, most of their reflections and the posterior discussion by the students were based on the reading as if the events, characters and opinions included in the tale were true. For most students, this fictional short story was probably the first deliberate pedagogical contact with a reality that they were alien to- transgender people-within a context that they were very familiar with-PE and sports education. In this regard, fiction (at least this piece of fiction) can be a valid and powerful source of understanding and creating dialogue. Second, most of the students' comments that we have situated in the domain of alterity took place in later stages of the activity, especially regarding the comments gathered from the blog. These comments were often related to characters from the fictional piece or were responses to opinions expressed by other students. This may be a sign of the impact the activity had in the swing towards alterity. Therefore, if any change was noted in any particular student, it was probably due to the combination of the imagining of transgender people inspired by the reading of the fictional tale as well as further reflection as a consequence of dialogue between different points of view.

In spite of the possibilities, we acknowledge that our fictional tale and its pedagogical use are partial, situated and restricted by our own subjectivities, particularly by the fact that none of us is a transgender person. Therefore, some obvious criticism is that by using it as a representation of transgender people's experience of sports, $\mathrm{PE}$ and physical activity we may be appropriating the voice of a transgender person. When approached and willing to share their stories, counting on 
the voices of transgender people might enrich future pedagogical proposals. In particular, it would turn encounter with trans-identified persons from a potentially unlikely possibility that might happen in the future, into an actual performance happening in the present, in everyday's life, something that was missing in our pedagogical approach to imagining transgender. However, we should stress that any approach to this issue, including those of particular transgender persons, would be limited and restricted to their subjectivities. Consequently, there is not a single or correct way to accurately represent a transgender person's experiences, but different approaches might contribute to a better understanding and acceptance of gender diversity.

Finally, we have learnt from this experience that the imagining of transgender people, and in general the imagining of the other, has consequences and, as so, is a moral act. While the ethics of alterity does not provide us with principles or rules that we should follow, it offers orientation by which we might measure the humanity of our imagining of the other. Once encountered, the face of transgender remains present. And it is our responsibility to do as much as we can do to 'interrogate and to disturb the complacency of whatever regnant theories and discourses we have come to accept as normative' (Holland, 2003, p. 186). In this regard, we hope to have given a sensitive response to our own encounter with the face of transgender people, by which we felt obliged to act both as researchers and educators.

\section{Acknowledgements}

The authors would like to thank the students who participated in this experience and the two anonymous reviewers for their insightful and useful comments.

\section{Funding}

This work was supported by the Ministry of Education and Ministry of Science and Technology of Spain [grant number EDU2009-06815-E/EDUC] and [grant number DEP2011-28190], respectively.

\section{References}

Braun, V., \& Clarke, V. (2006). Using thematic analysis in psychology. Qualitative Research in Psychology, 3(2), 77-101. doi:10.1191/1478088706qp063oa

Butler, J. (1990). Gender Trouble. Feminism and the subversion of identity. New York, NY: Routledge.

Butler, J. (1993). Bodies that matter. On the discursive limits of 'sex'. New York, NY: Routledge.

Caudwell, J. (2014). [Transgender] young men: Gendered subjectivities and the physically active body. Sport, Education and Society, 19, 398-414. doi:10.1080/13573322.2012.672320

Ellsworth, E. A. (1997). Teaching positions: Difference, pedagogy, and the power of address. New York, NY: Teachers College Press.

Frank, A. W. (2004). The renewal of generosity. Illness, medicine, and how to live. Chicago, IL: The University of Chicago Press.

Halberstam, J. (1995). Skin shows. Gothic Horror and the technology of monsters. New York, NY: Duke University Press. 
Holland, S. (2003). Levinas and otherwise-than-being (tolerant): Homosexuality and the discourse of tolerance. $\mathcal{F} A C, 23,165-189$.

Kristeva, J. (1982). Powers of horror: An essay on abjection. New York, NY: Columbia University Press.

Levinas, E. (1974). Otherwise than being, or beyond essence. Dordrecht: Kluwer.

O'Neil, M. E., McWhirter, E. H., \& Cerezo, A. (2008). Transgender identities and gender variance in vocational psychology recommendations for practice, social advocacy, and research. Fournal of Career Development, 34, 286. doi:10.1177/0894845307311251

Robbins, J. (Ed.). (2001). Is it righteous to be?: Interviews with Emmanuel Levinas. Stanford, CA: Stanford University Press.

Shepherd, L. (2003). Face to face: A call for radical responsibility in place of compassion. St. Fohn's Law Review, 77, 445-514.

Shilling, C. (2007). Embodying sociology: Retrospect, progress and prospects. London: SAGE.

Smith, B. (2008). Imagining being disabled through playing sport: The body and alterity as limits to imagining others' lives. Sport, Ethics and Philosophy, 2(2), 142-157. doi:10.1080/ 17511320802222040

Sparkes, A., \& Smith, B. (2009). Judging the quality of qualitative inquiry: Criteriology and relativism in action. Psychology of Sport and Exercise, 10, 491-497. doi:10.1016/j. psychsport.2009.02.006

Spindler, J. (2008). Fictional writing, educational research and professional learning. International Fournal of Research E Method in Education, 31(1), 19-30. doi:10.1080/17437270801919867

Stryker, S. (1998). The transgender issue: An introduction. Fournal of Lesbian and Gay Studies, 4(2), 145-158.

Stryker, S. (2006). My words to Victor Frankenstein above the village of Chamounix: Performing transgender rage. In S. Stryker \& S. Wittle (Eds.), The transgender studies reader (pp. 244-256). New York, NY: Routledge.

Tinning, R. (2002). Toward a "modest pedagogy": Reflections on the problematics of critical pedagogy. Quest, 54, 224-240. doi:10.1080/00336297.2002.10491776 